\title{
Evaluation of Mechanical Performance of High Performance Hybrid Fiber Reinforced Concrete Containing Micro Silica
}

\author{
N Venkata Narasimha Prabath", Ramadoss $\mathbf{P}$ \\ Department of Civil Engineering, Pondicherry Engineering College, Pondicherry, India \\ Received October 16, 2021; Revised December 7, 2021; Accepted December 27, 2021
}

\section{Cite This Paper in the following Citation Styles}

(a): [1] N Venkata Narasimha Prabath, Ramadoss P, "Evaluation of Mechanical Performance of High Performance Hybrid Fiber Reinforced Concrete Containing Micro Silica," Civil Engineering and Architecture, Vol. 10, No. 1, pp. 210 - 223, 2022. DOI: 10.13189/cea.2022.100118.

(b): $N$ Venkata Narasimha Prabath, Ramadoss P (2022). Evaluation of Mechanical Performance of High Performance Hybrid Fiber Reinforced Concrete Containing Micro Silica. Civil Engineering and Architecture, 10(1), 210 - 223. DOI: 10.13189/cea.2022.100118.

Copyright $\mathrm{C} 2022$ by authors, all rights reserved. Authors agree that this article remains permanently open access under the terms of the Creative Commons Attribution License 4.0 International License

\begin{abstract}
In the extended use of concrete in military applications, runway pavements and infrastructures, concrete is subjected to heavy impact loads that vary both in velocity and intensity. The addition of fibers in high performance concrete (HPC) can overcome its shortcomings such as brittleness, high shrinkage and less resistance to impact and also improve the ductile behavior and energy absorption capacity. In this study, development on strengthening of HPC using steel and Polypropylene fibers was focused. Moreover, an inclusion of volume fractions of both steel and polypropylene fibers, leads to an increase in the mechanical properties of concrete matrix. The present study represents the adding steel and Polypropylene fibres at $0.5,1.0,1.5$, and 0.25 , $0.5,1 \%$ by volume of concrete, respectively. A concrete mix has been designed to achieve the M60 grade concrete, mixes proportioned for FRC to determine the compressive strength, split tensile strength and flexural strength of high performance hybrid fiber reinforced concrete at 28 days. The experimental results showed that the use of hybrid fibers with $1.5 \%$ steel and $1 \%$ Polypropylene fiber in HPC concrete has improved the strength of the concrete by $36 \%$ and $25.1 \%$ HPC with single fibers. The statistical tool was formulated to predict the strength properties of fiber reinforced concrete (i.e., compressive, flexural and split tensile strengths). The response surface method (RSM) was used to analyze the data and develop a regression equation. RSM was able to predict the experimentally tested values within an acceptable range.
\end{abstract}

Keywords High Performance Concrete, Hybrid Fiber Reinforced Concrete, Crimped Steel Fiber, Polypropylene Fiber, Micro Silica, Mechanical Properties, Response Surface Method

\section{Introduction}

The widespread usage of concrete in constructions is owing to a number of factors, including its mechanical strength, ease of manufacturing, and moulding, as well as its affordable cost [1]. Fibers can be integrated into the concrete as fabrics and textiles, or they can be randomly spread throughout the matrix. Nonetheless, for economic reasons, the usage of spread fibres has become more prevalent [2]. The combination of using light weight aggregates together with reinforcing fibers has been introduced in order to improve the material and mechanical characteristics of the lightweight concrete in [3] both fresh and hardened state and has led to the development of the fiber reinforced lightweight concrete whose application has been reported in several experimental and real case studies [4]. Over decades in an attempt to remedy the inherent disadvantages of plain concrete, Fibers are incorporated into the concrete mix, generally known as fibre reinforced concrete, to improve the mechanical characteristics of concrete, notably for its tensile and 
post-cracking behavior [5]

For example, High Strength Concrete (HSC) specimens including polyethylene, steel, carbon, and polypropylene fibres show, increased flexural strength and ductility while reducing crack width [6,7]. Hybridization of fibres is usually accomplished by combining two types of fibres in concrete, which improves the concrete's mechanical characteristics [8]. As a result, combining silica fume with fly ash yields an intriguing option that may be referred to as high-strength, high-performance concrete [9]. Flexural behavior is also enhanced to a degree. It also has the capacity to decrease concrete plastic shrinkage [10].

Banthia $\mathrm{N}$ et al. [11] have studied the effect of fiber synergy in the fiber reinforced concrete. In the study it was reported that the use of two or more types of fibers in a suitable combination has the potential to improve the mechanical properties of concrete. For those hybrid composites examined under flexure, there was a positive interaction between steel and cellulose fibers in all instances. Ramadoss Perumal [12] has investigated the HPSFRC with different $\mathrm{w} / \mathrm{c}$ in the range of $0.25-0.40$, steel fiber volume fraction of $0.5-1.5 \%$ with aspect ratio of 40-80. From that it was observed that steel fiber volume fraction $\mathrm{Vf}=1.5 \%$ in HPC results in significant improvement in flexural tensile strength. They developed statical models for the flexural and splitting tensile strength of HPSFRC, in that $90 \%$ of estimated values are within $\pm 5 \%$ of actual values. P Ramadoss [13] has studied on HPSFRC that the variables investigated are steel fiber volume fraction (0 to $1.5 \%$ ), silica fume replacement (5 and 10\%) and water-to-binder ratio $(0.25,0.30,0.35$ and 0.40$)$. Based on the test data, using regression analysis, empirical expression to predict 28-day tensile strength of HSFRC in terms of fiber reinforcing index was developed. $P$ Ramadoss \& K Nagamani [14] have investigated the compressive strength of high-performance steel fiber reinforced concrete with a volume fraction $\left(\mathrm{V}_{\mathrm{f}}=0.0,0.5\right.$, 1.0 and $1.5 \%$ ) with fiber aspect ratios of 80 and 53 with incorporation of silica fume ranges from 5 to $15 \%$ as cementitious material. Different $(\mathrm{w} / \mathrm{cm})$ rations from 0.25 to 0.4 . It was observed that the proposed model was found to have a good accuracy $\pm 3 \%$ to the actual value. $R$ Perumal [15] has developed multivariate linear regression models for the prediction of 28-day strength and toughness properties of HPSFRC and from the models the absolute variations obtained are $1.09 \%, 2.36 \%$, and $3.36 \%$ for compressive, flexural, and splitting tensile strengths, respectively. Eethar Thanon Dawood et al. [16] have reported that hybrid fibers of $0.25-5 \%$ of palm fibers and $1.75 \%$ of steel fibers as volumetric fraction of HSFC mixes significantly improved the compressive strength. Also, they found that the flexural strength of HSFC was increased by about $36 \%$ than that of conventional mix with $1.5 \%$ steel fiber volume fraction.

The concrete specification will no longer allow for the selection of $w / \mathrm{cm}$. Chemical admixtures will continue to improve the durability of concrete with careful selection and application. In addition, the synergetic impact of hybrid fibre on concrete flexural characteristics and the associated fibre reinforcing mechanism were investigated and addressed. Finally, mathematical formulae were established based on a new complete fibre reinforcing index to estimate the flexural loads, deflections, and toughness of HFRC with different hybrid fibre characteristics. More research is required to demonstrate the performance of high-strength concrete reinforced with steel and polypropylene fibres due to several chemical and physical transformations of the paste and aggregates, which result in changes in the mechanical performance and durability of the concrete. Our recommended fibres are composites that have been produced in earlier investigations and have better ductility and strain hardening characteristics.

The following is how the rest of the paper is organized: Following this chapter of introduction, section 2 analyses current existing literatures; section 3 describes the experimental examination and also shows the testing methods. The results of the experimental and computer modelling are shown in Section 4. Finally, the conclusion section draws the section to a close with a look towards the future scope.

\section{Proposed Methodology}

Generally, in the construction RC structures, strength and durability are especially important in recent times. The main challenges which affect the performance of structures are heavy wind, earthquake, etc.; to avoid these issues, the proposed methodology introduced a new method. In this methodology, we focused to develop strengthening concrete using HPC, HSC, synthetic fibers, and hybrid fibers. In this evaluation process, three different structures are used, i.e., cube, cylinder, and prism along with fiber properties. The fibers act as an eco-friendly nature, nonabrasive, high specific strength, and good mechanical properties and toughness. The HyFRC specimens were cast and tested at 28 days curing to find the structural properties of concrete composites.

\subsection{Materials, Mixtures, and Specimens Preparation}

In the experimental investigation examines the effects of adding steel fibers, polypropylene fibers and hybrid fibers with different ratios on HPC and HSC concretes. The fibers which are utilized in this examination are steel fibers $(0$, $0.5,1$, and $1.5 \%)$ and polypropylene fibers $(0.25,0.5$, and $1 \%)$. An adequate number of cubes, cylinders, and prisms are thrown, and these specimens are investigated for compressive strength, split tensile strength and flexural strength at 28 days of curing period. Table 1 shows the physical properties of fibers. The mix proportions of HPC and HSC are depicted in Table 2. 
Table 1. Properties of fiber

\begin{tabular}{|c|c|c|c|c|c|c|}
\hline Fiber & Length $(\mathbf{m m})$ & Diameter $(\mathbf{m m})$ & Aspect ratio & $\begin{array}{c}\text { Ultimate tensile } \\
\text { strength (MPa) }\end{array}$ & $\begin{array}{c}\text { Modulus of } \\
\text { elasticity }\end{array}$ & Density $\left(\mathbf{k g} / \mathbf{m}^{\mathbf{3}}\right)$ \\
\hline Steel Fiber & 36 & 0.45 & 80 & 1100 & $200(\mathrm{GPa})$ & 7850 \\
\hline Polypropylene fiber & 12 & 0.02 & 600 & 400 & $6.9(\mathrm{MPa})$ & 910 \\
\hline
\end{tabular}

Table 2. Basic concrete mix design

\begin{tabular}{|c|c|c|c|c|c|c|c|c|c|}
\hline \multirow{2}{*}{$\begin{array}{c}\text { Mix } \\
\text { design }\end{array}$} & \multirow{2}{*}{$\mathbf{w} / \mathbf{b}$ ratio } & \multirow{2}{*}{$\begin{array}{c}\text { Cement } \\
\text { (kg) }\end{array}$} & \multirow{2}{*}{$\begin{array}{c}\text { Silica fume } \\
\text { (kg) }\end{array}$} & \multirow{2}{*}{ Water (kg) } & \multirow{2}{*}{$\begin{array}{l}\text { C.A } \\
\text { (kg) }\end{array}$} & \multirow{2}{*}{$\begin{array}{l}\text { F.A } \\
\text { (kg) }\end{array}$} & \multirow{2}{*}{$\begin{array}{c}\text { Super plasticizer } \\
(\%)\end{array}$} & \multicolumn{2}{|c|}{ Fiber content $\left(V_{f}\right)$} \\
\hline & & & & & & & & Steel (\%) & Polypropylene (\%) \\
\hline $\mathrm{HSC}$ & 0.38 & 460 & 0 & 175 & 1168 & 618 & 1.75 & 0 & 0 \\
\hline $\mathrm{HPC}$ & 0.38 & 392 & 68 & 175 & 1168 & 618 & 1.75 & $05,1,1.5$ & $0.25,0.5,1$ \\
\hline
\end{tabular}

The various tests that are carried out to determine the characteristics of concrete are done according to the Indian standards. The material used in this investigation consists of Ordinary Portland Cement (OPC), coarse aggregate, fine aggregate and super plasticizer. The fiber properties of steel and polypropylene are shown in Table 2. The materials such as coarse aggregate, fine aggregate, sand, cement, water, fibers, and super plasticizer were used in this investigation. A total of 17 specimens are prepared by varying properties. The mix design quantities of HSC are 0.38 in water cement ratio; cement is used by $460 \mathrm{~kg}$. The fine aggregate is used by mass of the content as $618 \mathrm{~kg}$ and the coarse aggregate as $1168 \mathrm{~kg}$. The super plasticizer is added by $1.75 \%$ in HSC. The mixing quantities of HPC and HFHPC for cement, fine aggregate, coarse aggregate, water, silica fume, super plasticizer are $392 \mathrm{~kg}, 618 \mathrm{~kg}$, $1168 \mathrm{~kg}, 175 \mathrm{~kg}, 68 \mathrm{~kg}$ and $1.75 \%$, respectively. The fiber percentages which are used in HPC are $0.5 \%, 1 \%$, and $1.5 \%$ in steel fibers and $0.25 \%, 0.5 \%, 1 \%$ in polypropylene fiber and the water cement ratio is 0.38 . The mechanical properties of FRC are mainly dependent upon fiber parameter, fiber content, matrix strength, and fiber matrix interaction.

\subsection{Mix Design and Preparation of Specimens}

All the materials were collected and stored in the laboratory before the mixing of the concrete. The cement and aggregates were mixed for three minutes with premixed super plasticizer and water, and fibers added in another 3 mins continuously during mix, then we rest for three minutes, and then mixed again for two minutes. The mixer was turned off, and the concrete mixture was poured into various moulds based on the size of the specimens. Fibers were added to the concrete after the concrete mixture was prepared and stirred for five minutes to ensure that the fibres were evenly distributed throughout the concrete. Figure 1 (a), (b), and (c) illustrate the experimental setup.

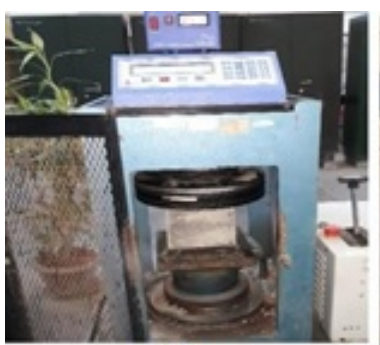

(a)

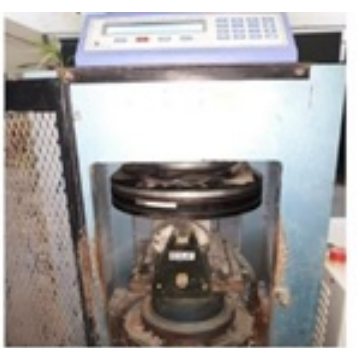

(b)

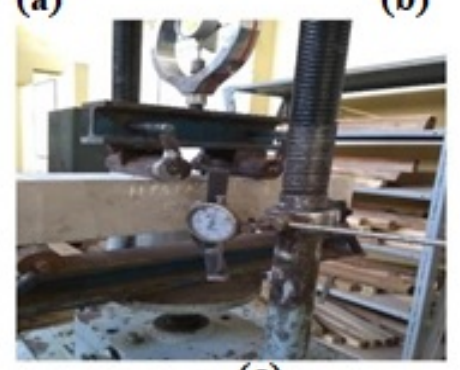

(c)

Figure 1. Testing Procedure (a) cube test setup, (b) cylinder test setup and (c) prism test setup

\subsection{Casting and Curing}

The casting of the test samples was carried out by dosing the materials, preparing the moulds and placing the concrete in the moulds. When placing the fresh concrete in the mould, great care was taken to get rid of the trapped air using a table vibrator to achieve maximum strength. After leveling the fresh concrete in the moulds, it was allowed to dry for 24 hours. Curing is an important process to prevent concrete samples from losing moisture while building the required strength. All concrete samples were cured in water at room temperature for 28 days. After curing, the concrete samples were removed from the curing tank and air dried for testing on cured concrete. Three test pieces were cast for each type of test and for each mixture. After 28 days, the compressive strength, the flexural strength and the tensile strength were tested. 


\subsection{Testing Methods}

Compressive strength test was conducted on cube specimens of size $150 \mathrm{~mm}$ X $150 \mathrm{~mm}$ X $150 \mathrm{~mm}$ as per IS: 516-2004 [17]. Split tensile strength test was carried out on cylinder specimens of size $100 \mathrm{~mm}$ X $200 \mathrm{~mm}$ as per ASTM C496-1990 [18]. Flexural strength was carried out on beam specimens of size $100 \mathrm{~mm}$ X $100 \mathrm{~mm}$ X $500 \mathrm{~mm}$ at 28 days as per ASTM C78-1994 [19] specification. Three samples were used for computing average strength of a concrete mix in each test.

\section{Results and Discussion}

From the experimental investigation, mechanical performance of HSC, HPC and HyFRC were obtained and discussed.

\subsection{Compressive Strength}

The compressive strength is one of the most important properties of hardened concrete for design of concrete elements. The 28 days cured samples were tested for the compressive strength of concrete. In this study M60 grade concrete (HSC) has been designed as per IS: 10262-2009 [20] standard; mixes were proportioned for HPC and HyFRC. The control samples were prepared without the accumulation of the fibers. The fiber reinforced samples $(9$
No's) were prepared by the accumulation of hybrid fibers. The concrete mixes are observed to be stiff and having low workability. The compressive strength test results obtained are given in Table 3.

Table 3 shows the mechanical properties of concrete specimens tested at 28 days of cured specimens. The compressive strength of HSC specimen achieved is 68.85 $\mathrm{MPa}$ for $\mathrm{w} / \mathrm{c}=0.38$. The 28-daystrength of HPC can be increased up to $75.05 \mathrm{MPa}$ for $0.38 \mathrm{w} / \mathrm{c}$. If the steel fibers and polypropylene fibers are added separately with the percentage of $0.5 \%, 1 \%$ and $1.5 \%, 0.25 \%, 0.5 \%$ and $1 \%$ in HPC, the compressive strength has been increased for both w/c ratios. Moreover, the addition of hybrid fibers i.e., different percentages of steel and polypropylene fibers increase the strength of the concrete and reduces the crack propagation.

The synergetic effects on flexural behavior have been noticed in the samples containing hybrid fibers. As the dosage of polypropylene and steel fibers are enhances the performance of concrete also enhances. The greatest apparent synergy was noticed in the hybrid fibers with a combination of polypropylene and straight steel fibers. The control samples and samples only with accumulation of polypropylene fibers fail in a brittle manner with well-ordered cracks on the surface while; the ductile failure has been noticed in samples containing steel fibers. The high strength fiber reinforced concrete mechanical properties are examined. The test results are depicted in the Figure 2 respectively.

Table 3. 28 day compressive, split tensile and flexure strengths of High performance Hybrid fiber reinforced concrete (w/b: 0. 38).

\begin{tabular}{|c|c|c|c|}
\hline Mix ID & $\begin{array}{c}\text { Cube Compressive strength at 28 } \\
\text { days (MPa) }\end{array}$ & $\begin{array}{c}\text { Split tensile strength at 28 } \\
\text { days (MPa) }\end{array}$ & $\begin{array}{c}\text { Flexural strength at 28 days } \\
\text { (MPa) }\end{array}$ \\
\hline HSC & 68.85 & 5.49 & 6.99 \\
\hline HPC & 75.05 & 5.75 & 9.12 \\
\hline HPSFRC-0.5 & 77.85 & 6.26 & 9.14 \\
\hline HPSFRC-1 & 82.5 & 6.48 & 10.35 \\
\hline HPSFRC-1.5 & 88.65 & 7.51 & 8.54 \\
\hline HPPFRC-0.25 & 75.95 & 5.84 & 8.64 \\
\hline HPPFRC-0.5 & 77.65 & 5.97 & 8.87 \\
\hline HPPFRC-1 & 79.4 & 6.25 & 9.25 \\
\hline HP-HYC (S0.5, P0.25) & 78.55 & 6.45 & 9.38 \\
\hline HP-HYC (S0.5, P0.5) & 79.68 & 6.93 & 9.69 \\
\hline HP-HYC (S0.5, P1) & 82.54 & 7.13 & 9.94 \\
\hline HP-HYC (S1, P0.25) & 83.75 & 7.16 & 10.25 \\
\hline HP-HYC (S1, P0.5) & 85.5 & 7.48 & 10.39 \\
\hline HP-HYC (S1, P1) & 86.85 & 7.89 & 10.47 \\
\hline HP-HYC (S1.5, P0.25) & 90.05 & 8.1 & 10.58 \\
\hline HP-HYC (S1.5, P0.5) & 92.25 & 8.69 & 10.79 \\
\hline HP-HYC (S1.5, P1) & 93.9 & 9.37 & \\
\hline
\end{tabular}




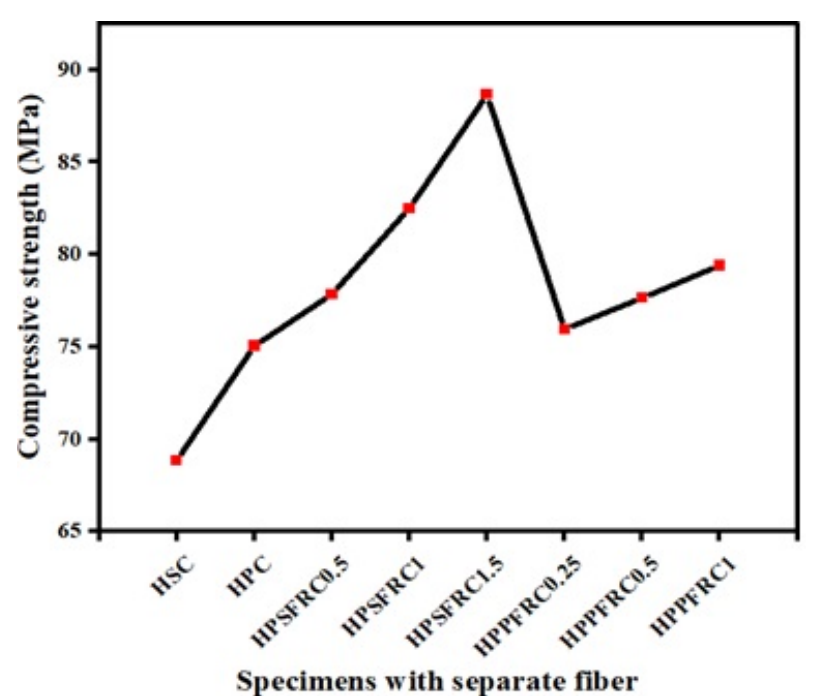

(a) Compressive strength results for single fibers volume fraction

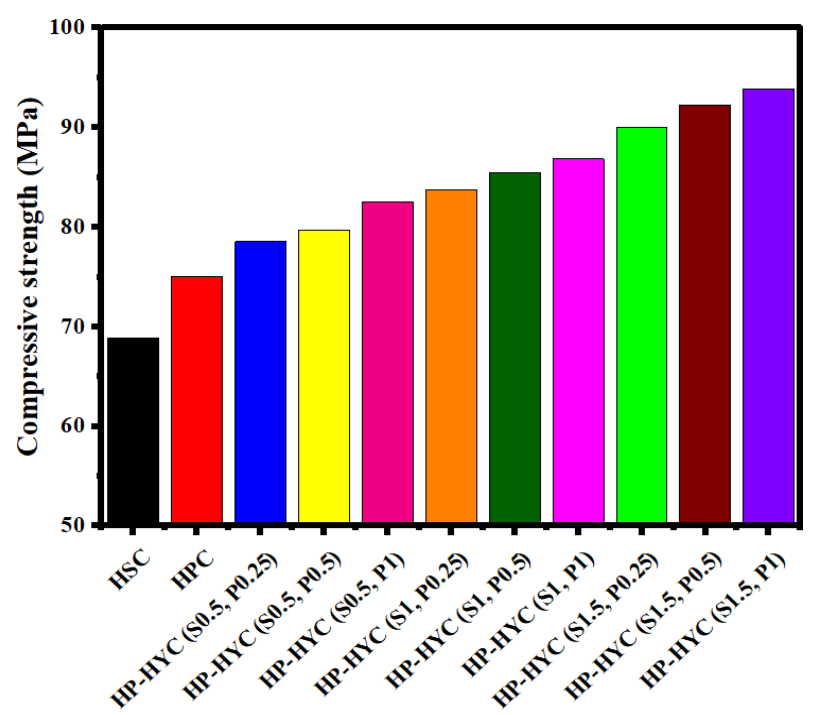

Hybrid fiber volume fraction (\%)

(b) Compressive strength results for hybrid fiber reinforced concrete

Figure 2. Experimental values of Compressive strength at 28-days

\subsection{Split Tensile Strength}

The split tensile strength of concrete is the most important in terms of cracking behavior, damping action, stiffness, and durability of the concrete. The shear loads of the concrete are determined considering the split tensile strength of the concrete. In the present study, split cylinder test has been performed to study the split tensile strength of concrete. The 28 days water cured samples are utilized for this study. The samples are taken from the curing tank left to dry for 24 hours. These samples are placed in the compression testing machine. The load has been applied gradually until the failure of the sample.

The split tensile strength of HPC increases with increase in percentage of fiber percentages. Table 3 and figure 3 show the result of split tensile strength which occurs in all the specimens for both w/c ratios. The tensile strength is lower than the compressive strength of concrete mainly due to the ease with which cracks can develop under high-pressure loads. This makes high-strength concrete more brittle and stiffer. Here, HSC for $0.38 \mathrm{w} / \mathrm{c}$ is 5.49 $\mathrm{MPa}$ at 28 days of curing in HSC specimens. For the comparison of HSC and HPC specimens, HSC requires more strength; that means HPC attains higher strength than HSC. In addition, the strength of HPC has been added because of including fibers. Specimens with separate fibers attain more value than HPC i.e., 6.26, 6.48, 7.51 in HPSFRC and 5.84, 5.97, 6.25 MPa in HPPFRC for 0.38 w/c. Hybrid specimen combines the fiber percentage of steel and polypropylene. The maximum split tensile strength achieves 9.37 in $0.38 \mathrm{w} / \mathrm{c}$ after 28 days of curing. The split tensile strength increased value can be shown in figure 3 for $0.38 \mathrm{w} / \mathrm{c}$ ratios.

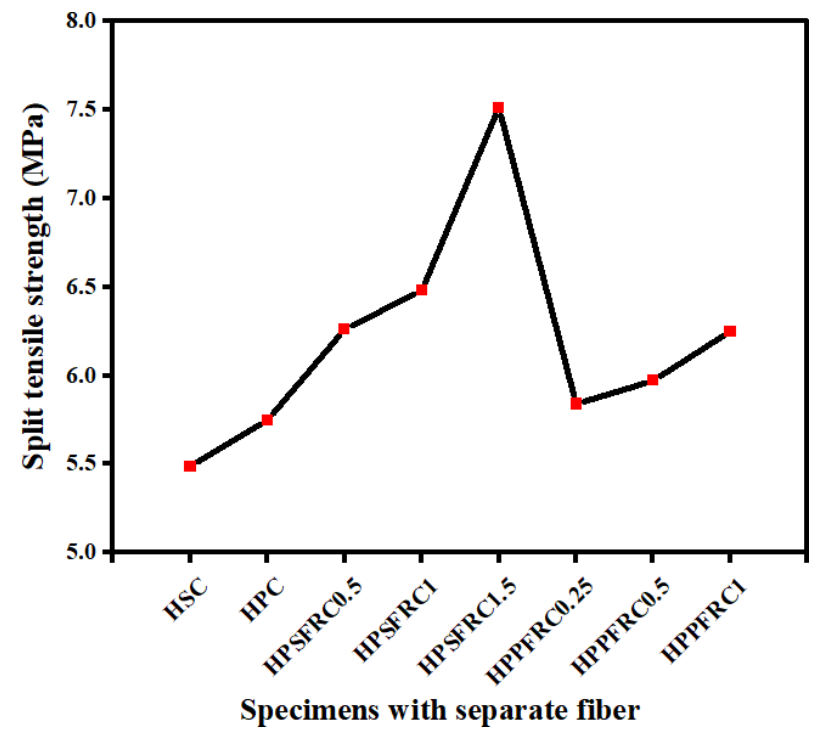

(a) Split tensile strength Results for single fibers volume fraction

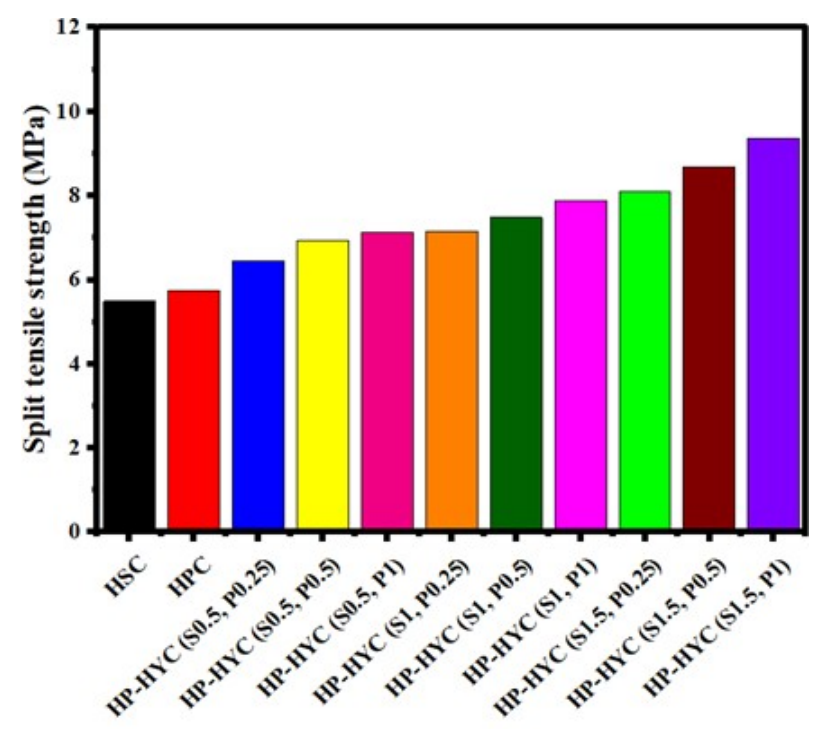

Hybrid fiber volume fraction (\%)

(b) Split tensile strength Results for Hybrid fibers

Figure 3. Experimental result for split tensile strength at 28 days 


\subsection{Flexural Strength}

The High-Performance Concrete (HPC) exhibits better performance and constructability than control concrete. The normal and special materials are acclimated to make these specially designed concretes that must meet an amalgamation of performance requisites. The strength of HPC is always higher than that of control concrete.

The flexural strength of various mixes at 28 days curing is given in Table 3 and 4 . The flexural strength of mixes at 28 days was found to be in the range of $6.9 \mathrm{MPa}-13.9 \mathrm{MPa}$ in $0.38 \mathrm{w} / \mathrm{c}$. The variation in flexural strength of the HSC mix and HPC mixes was significant. It was seen there was significant increase in flexural strength with age for all the mixes. In prism, the hybrid specimen performs the flexural range of $0.38 \mathrm{w} / \mathrm{c}$ is $9.25,9.38,9.69,9.94,10.25,10.39$, $10.47,10.58$, and $10.78 \mathrm{MPa}$.

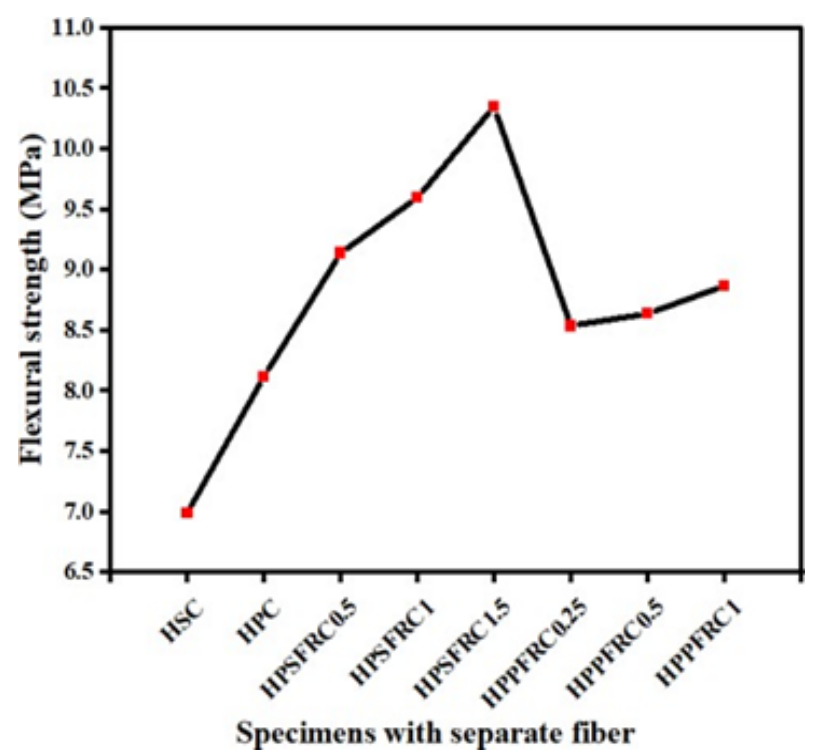

(a) Flexure strength Results for single fibers volume fraction

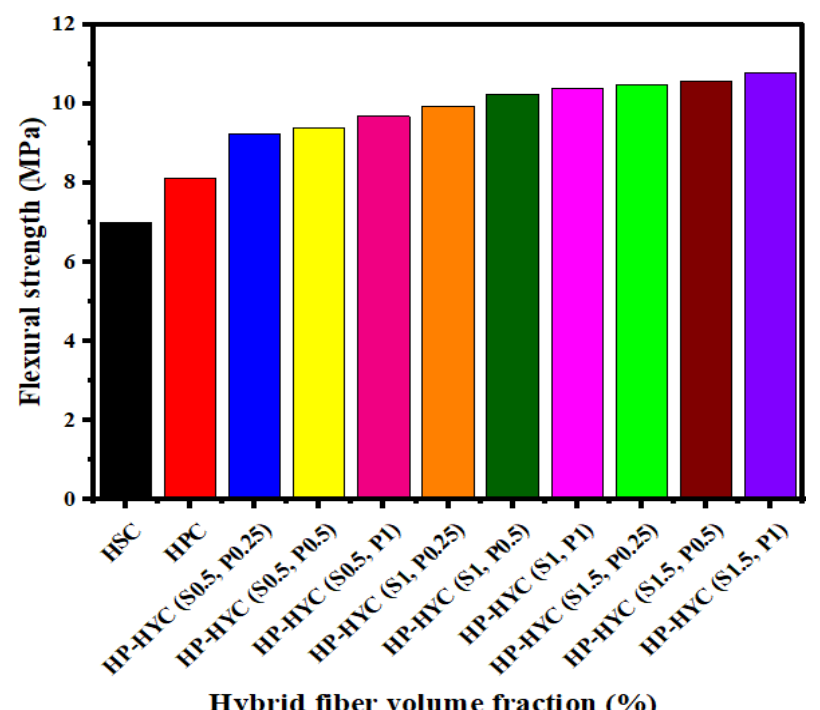

(b) Flexure strength Results for hybrid fibers

Figure 4. Experimental result for flexural strength at 28 days

\section{Response Surface Method}

Response surface methodology is a set of statistical methods that are used to improve or optimize a product's performance. This procedure mainly relates to the evaluation of the various factors that influence a concrete's performance characteristics [20]. A stepwise approach known as RSM can be used to improve a given response or to meet a set of specifications. This process involves designing an experiment that fits to the requirements of the given specification [21-25]. This paper shows that the "Strength properties" depends on the response of "steel fibers" and "polypropylene fibers". Second order polynomial expression was used for this research (given below).

$$
\mathrm{Z}=\mathrm{a}+\mathrm{bx}+\mathrm{cy}+\mathrm{dz}+\mathrm{ex} 2+\mathrm{fy} 2+\mathrm{gz} 2+\mathrm{hxy}+\mathrm{iyz}+\mathrm{jzx}
$$

The response variable $(\mathrm{f}(\mathrm{X}))$ represents the strength of concrete (i.e., Compression, split tensile and flexural strength), and the influence factors $x, y$ and $z$, represent the steel fiber, and polypropylene, respectively. This method is used to evaluate the effects of various variables on different subjects. It uses the regression analysis technique to examine the relationship between the various variables and the main effect. The values of the coefficients were obtained by using the MINITAB procedure after a linear regression analysis for the $95 \%$ confidence level.

Where $Z=$ Strength of concrete, $x=$ Cement, $y=$ Streel fiber proportion, $\mathrm{z}=$ polypropylene fiber proportion and $\mathrm{a}$, $\mathrm{b}, \mathrm{c}, \mathrm{d}, \mathrm{e}, \mathrm{f}, \mathrm{g}, \mathrm{h}, \mathrm{i}$ and $\mathrm{j}$ are the regression coefficients. The final regression model for strength of concrete in compression, split tensile and flexural of all mixes comprising all the terms are showed in equations 3-5, respectively.

Compressive strength $=109.81-(0.08905 *$ Cement $)+(3.446 *$ steel fibers $)+(5.55 *$ polypropylene $)+(3.92 *$ steel fiber * steel fiber $)$ $(1.095 *$ polypropylene fiber * polypropylene fiber) $+(0.44 *$ steel fiber $*$ polypropylene fiber $)$

Split tensile strength $=6.88-(0.00301 *$ Cement $)+$ $\left(0.565^{*}\right.$ steel fibers $)+(1.194 *$ polypropylene $)+$ $(0.425 *$ steel fiber $*$ steel fiber $)-(0.687 *$ polypropylene fiber * polypropylene fiber $)+(0.887$ $*$ steel fiber* polypropylene fiber)

Flexural strength $=15.09-(0.01761 *$ Cement $)+$ $(1.866 *$ steel fibers $)+(1.110 *$ polypropylene $)-$ $(0.32 *$ steel fiber * steel fiber $)-(0.403 *$ polypropylene fiber * polypropylene fiber $)-(0.107$ * steel fiber * polypropylene fiber)

The characteristics of formulated models of for compression strength, split tensile and flexural strength of all mixes were showed in Table 3. The adequacy of the formulated models was validated by their degree of correlation $\left(\mathrm{R}^{2}\right)$. A High degree of correlation $\left(\mathrm{R}^{2}\right)$ was 
observed for all models based on their values that were close to unity $\left(\mathrm{R}^{2}>0.97\right)$. This shows that the experimental values compressive strength, split tensile strength and flexural strength cannot be represented by the models only about $0.0069 \%, 0.03 \%$ and $0.0208 \%$, respectively. Response surface plot (3-D dimensional) was used to demonstrate the relationship between response and independent variables. Figures 5-7 show the response surface plots demonstrating the relationship between response (compressive strength, split tensile strength and flexural strength) and independent variables (Percentage of steel and polypropylene fibers) for all mixes. Combination of steel and polypropylene fiber proportion showed better strength properties compared to individual fibers proportion in to the concrete. Table 4 shows the experimental and predicted values of strength properties of concrete along with the residual error. The error (\%) less than $5 \%$ was obtained for the predicted response surface plot thereby showing $95 \%$ confidence level [26-32].

Table 4. Experimental strengths at 28 days and predicted values of HPC and HyFRC by using regression equation

\begin{tabular}{|c|c|c|c|c|c|c|}
\hline Mix ID & $\begin{array}{c}\text { Experimental } \\
\text { Compressive strength }\end{array}$ & $\begin{array}{c}\text { Predicted } \\
\text { Compressive } \\
\text { strength } \\
\end{array}$ & $\begin{array}{c}\text { Experimental } \\
\text { Split tensile } \\
\text { strength } \\
\end{array}$ & \begin{tabular}{|c|} 
Predicted \\
Split tensile \\
strength \\
\end{tabular} & $\begin{array}{c}\text { Experimental } \\
\text { Flexural strength }\end{array}$ & $\begin{array}{c}\text { Predicted } \\
\text { flexural } \\
\text { strength } \\
\end{array}$ \\
\hline HPC & 75.05 & 74.91 & 5.75 & 5.69 & 8.12 & 8.12 \\
\hline HPSFRC 0.5 & 77.85 & 77.61 & 6.26 & 6.08 & 9.14 & 9.14 \\
\hline HPSFRC1 & 82.5 & 82.27 & 6.48 & 6.69 & 9.60 & 9.6 \\
\hline HPSFRC1.5 & 88.65 & 88.89 & 7.51 & 7.50 & 10.35 & 10.35 \\
\hline HPPFRC0.25 & 75.95 & 76.22 & 5.84 & 5.95 & 8.54 & 8.54 \\
\hline HPPFRC0.5 & 77.65 & 77.41 & 5.97 & 6.12 & 8.64 & 8.64 \\
\hline $\begin{array}{l}\text { HP-HYC (S0.5, } \\
\mathrm{P} 0.25)\end{array}$ & 79.4 & 79.36 & 6.25 & 6.20 & 8.87 & 8.87 \\
\hline $\begin{array}{l}\text { HP-HYC (S0.5, } \\
\text { P0.5) }\end{array}$ & 78.55 & 78.98 & 6.45 & 6.45 & 9.25 & 9.25 \\
\hline HP-HYC (S0.5, P1) & 79.68 & 80.22 & 6.93 & 6.73 & 9.38 & 9.38 \\
\hline $\begin{array}{l}\text { HP-HYC (S1, } \\
\text { P0.25) }\end{array}$ & 82.54 & 82.28 & 7.13 & 7.03 & 9.69 & 9.69 \\
\hline HP-HYC (S1, P0.5) & 83.75 & 83.70 & 7.16 & 7.16 & 9.94 & 9.94 \\
\hline HP-HYC (S1, P1) & 85.5 & 84.99 & 7.48 & 7.55 & 10.25 & 10.25 \\
\hline $\begin{array}{l}\text { HP-HYC (S1.5, } \\
\text { P0.25) }\end{array}$ & 86.85 & 87.16 & 7.89 & 8.08 & 10.39 & 10.39 \\
\hline $\begin{array}{l}\text { HP-HYC (S1.5, } \\
\text { P0.5) }\end{array}$ & 90.05 & 90.38 & 8.1 & 8.09 & 10.47 & 10.47 \\
\hline HP-HYC (S1.5, P1) & 92.25 & 91.73 & 8.69 & 8.59 & 10.58 & 10.58 \\
\hline $\begin{array}{l}\text { HP-HYC (S0.5, } \\
\text { P0.25) }\end{array}$ & 93.9 & 94.01 & 9.37 & 9.34 & 10.79 & 10.79 \\
\hline
\end{tabular}




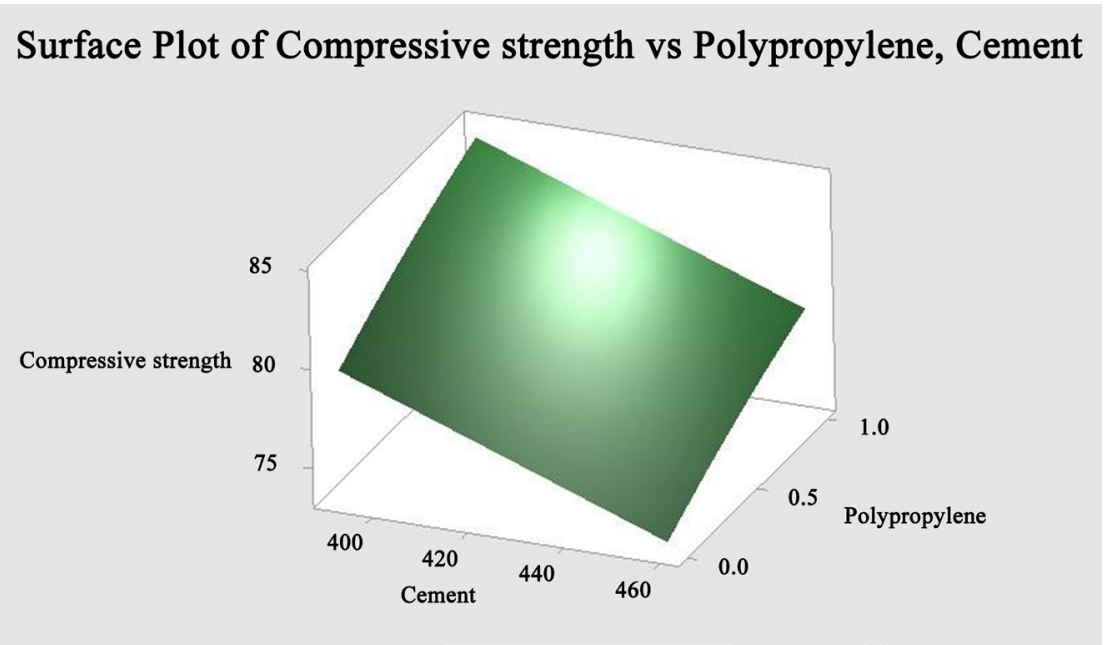

(a). Compressive strength Vs polypropylene and cement
Surface Plot of Compressive strength vs Polypropylene, Steel Fiber

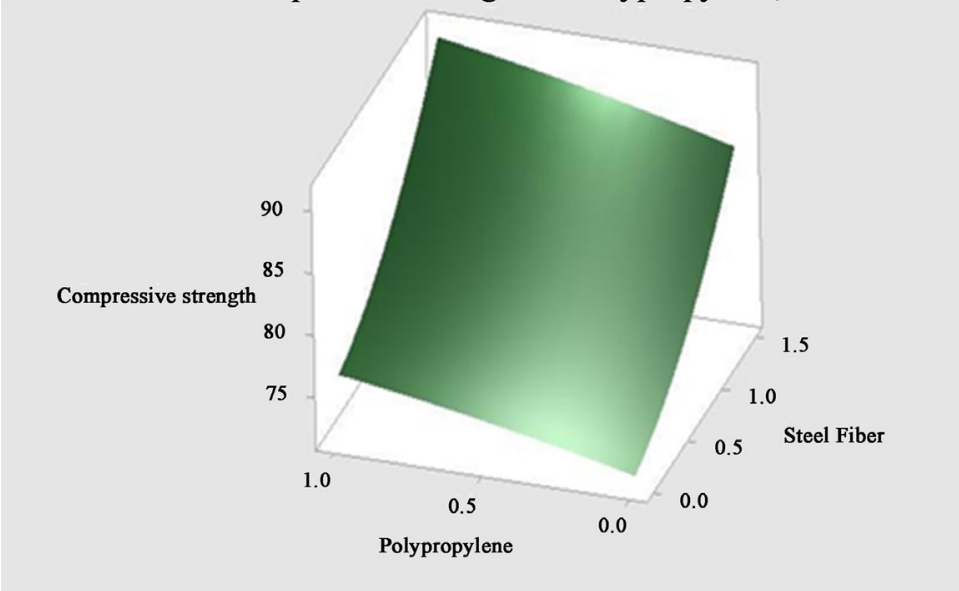

(b) Compressive strength Vs steel fibers and cement

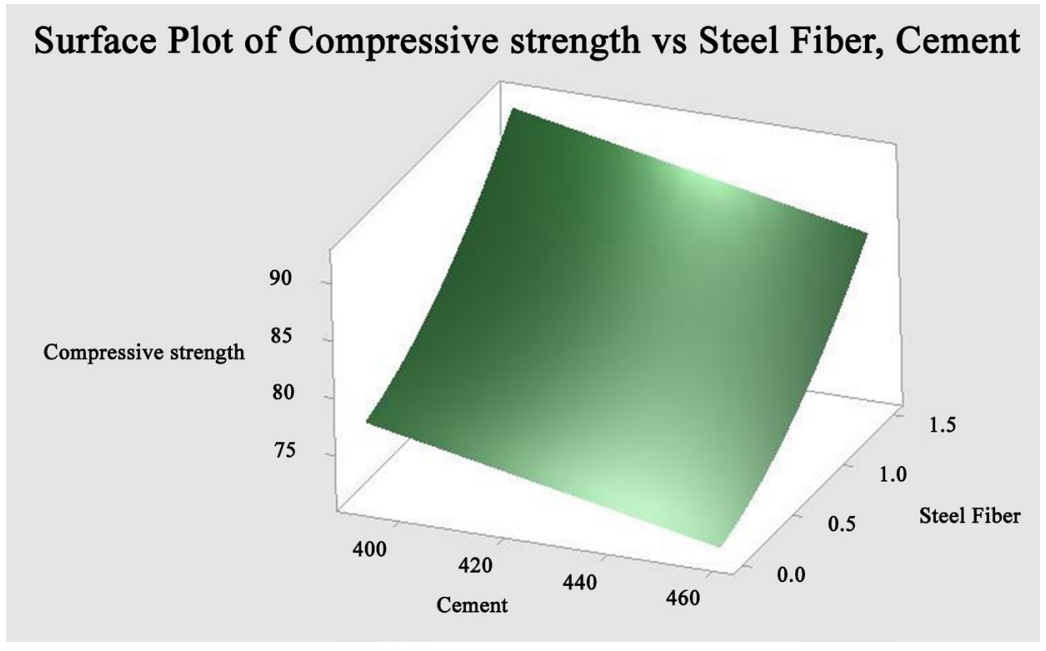

(c) Compressive strength Vs polypropylene and steel fibers

Figure 5. Surface plots for compressive strength 


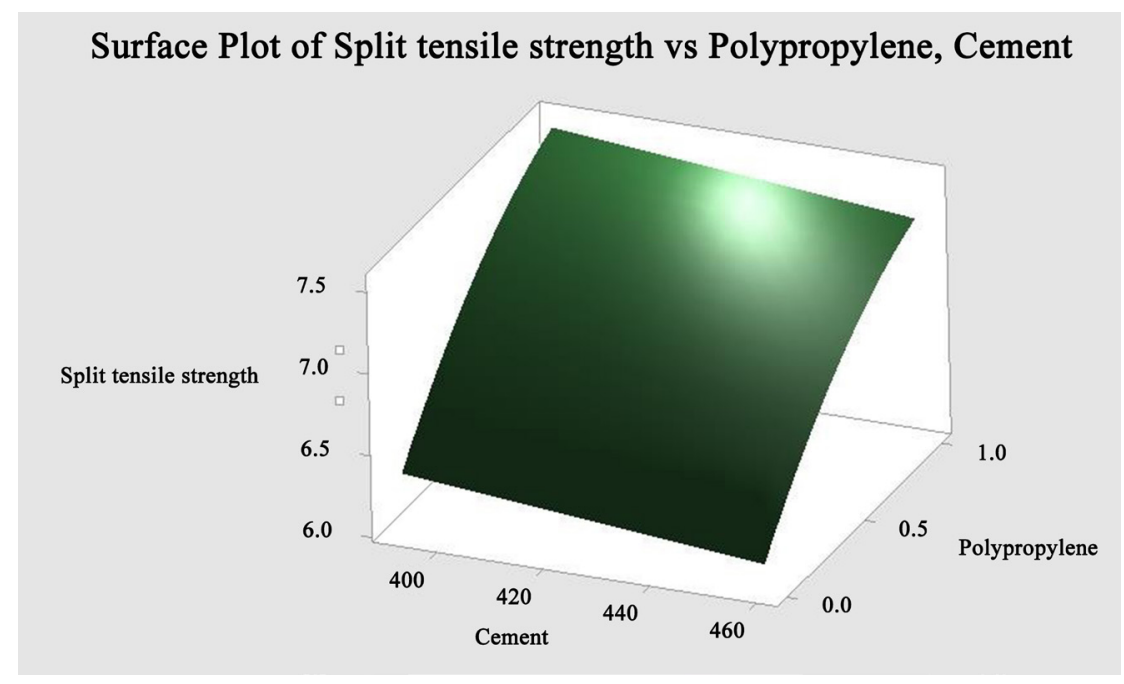

(a) Split tensile strength Vs polypropylene and cement

\section{Surface Plot of Split tensile strength vs Steel Fiber, Cement}

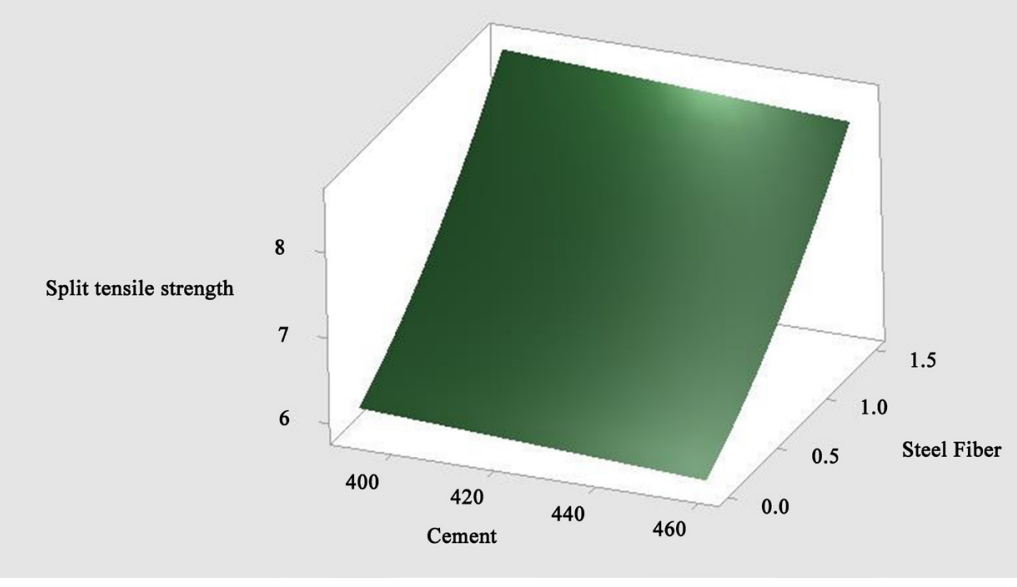

(b) Split tensile strength Vs steel fibers and cement

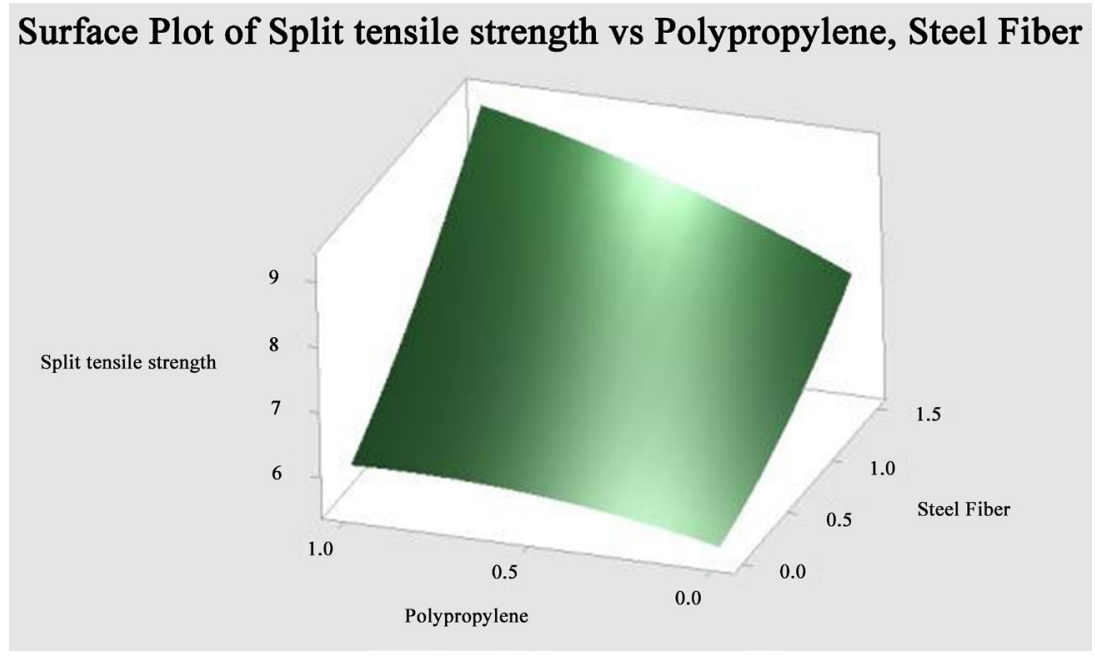

(c) Split tensile strength Vs polypropylene and steel fibers

Figure 6. Surface plots for split tensile strength 


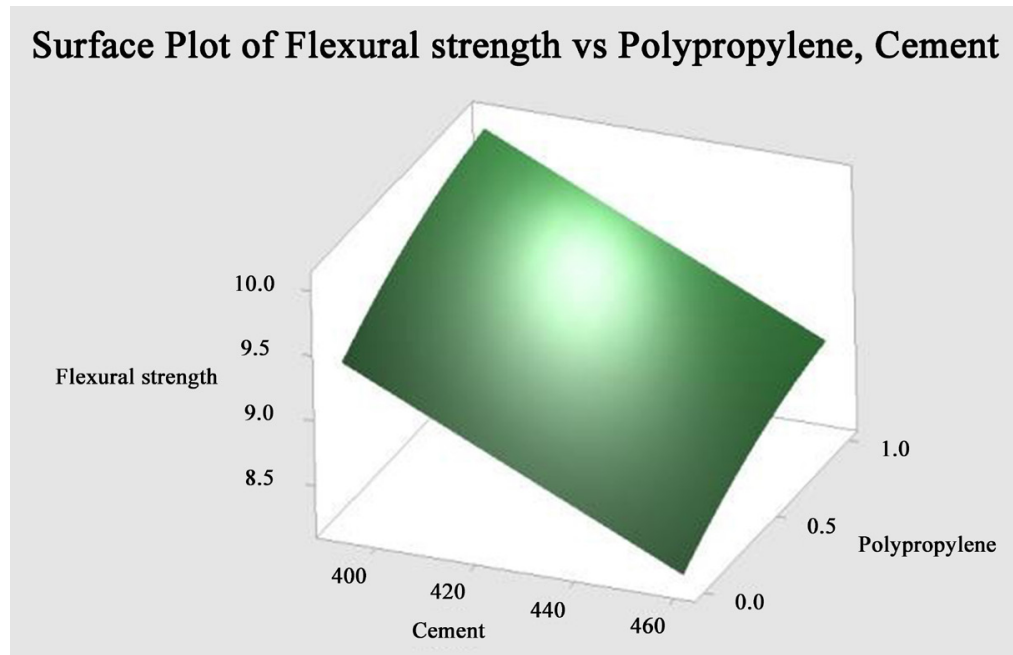

(a) Flexural strength Vs polypropylene and cement
Surface Plot of Flexural strength vs Steel Fiber, Cement

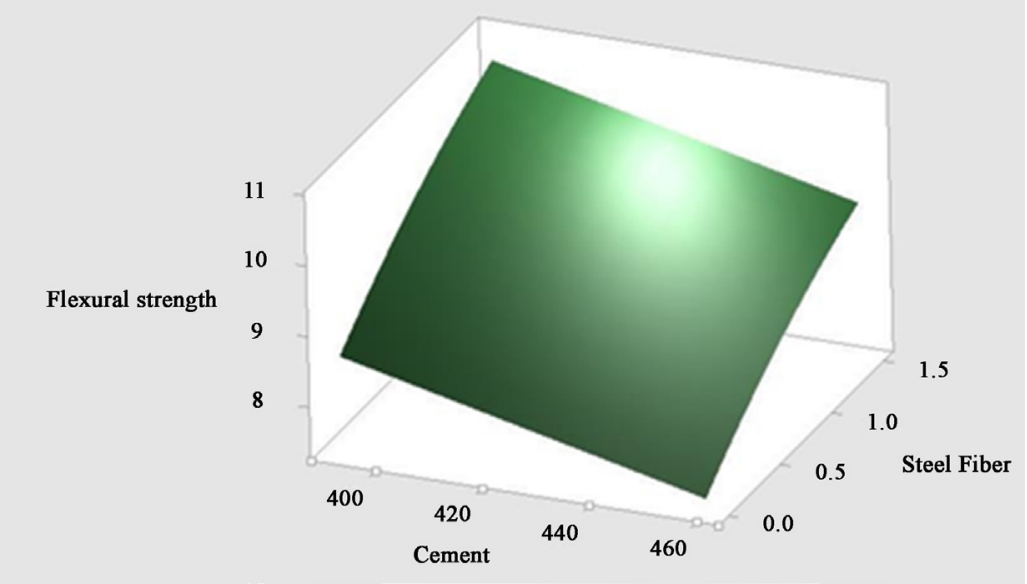

(b) Flexural strength Vs steel fibers and cement

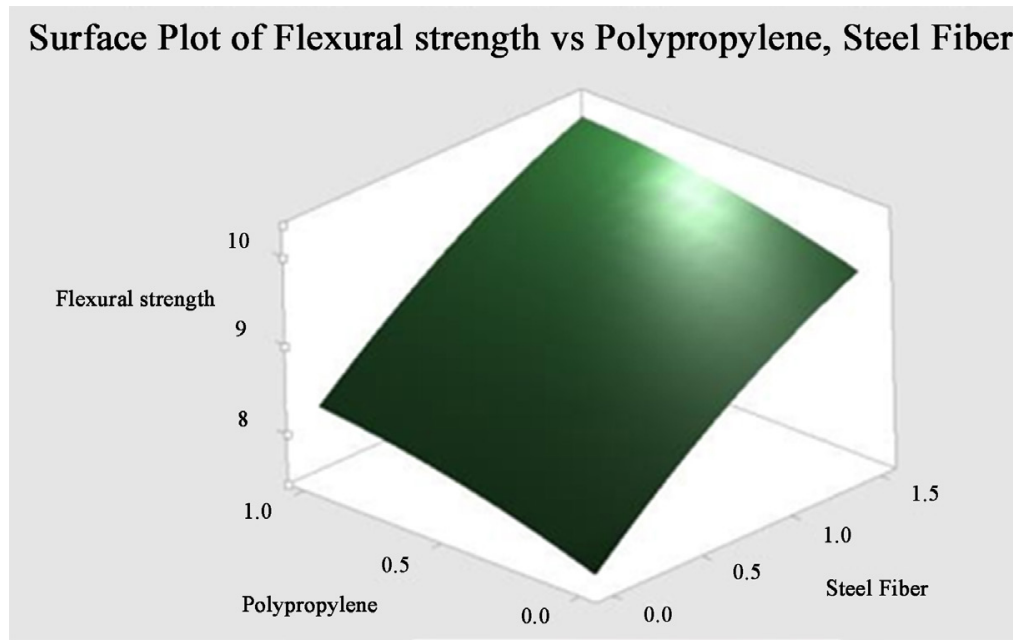

(c) Flexural strength Vs polypropylene and steel fibers

Figure 7. Surface plots for flexural strength 


\subsection{Residual Plots}

The graph illustrates the closeness of the predicted strength properties to the experimentally observed data. The error indicated by the points near the reference line was within acceptable range (Shown in Figures 8-10). From the compressive strength residual plot, the range of $0-0.25$ and $0.25-0.50$ the observed residual values were 7 and 2 respectively. Similarly, under the reference line 3 and 4 residual values were found to be in the range to 0 to -0.25 and -0.25 to -0.5 respectively.

For split tensile strength, the range of $0-0.1$ and $0.1-0.2$ the observed residual values were 9 and 2 respectively. Similarly, under the reference line 2 and 3, residual values were found to be in the range to 0 to -0.1 and -0.1 to -0.2 respectively. For flexural strength, the range of $0-0.05$ and $0.05-0.1$ the observed residual values were 4 and 4 respectively. Similarly, under the reference line 5 and 4, residual values were found to be in the range to 0 to -0.1 and -0.1 to -0.2 respectively.

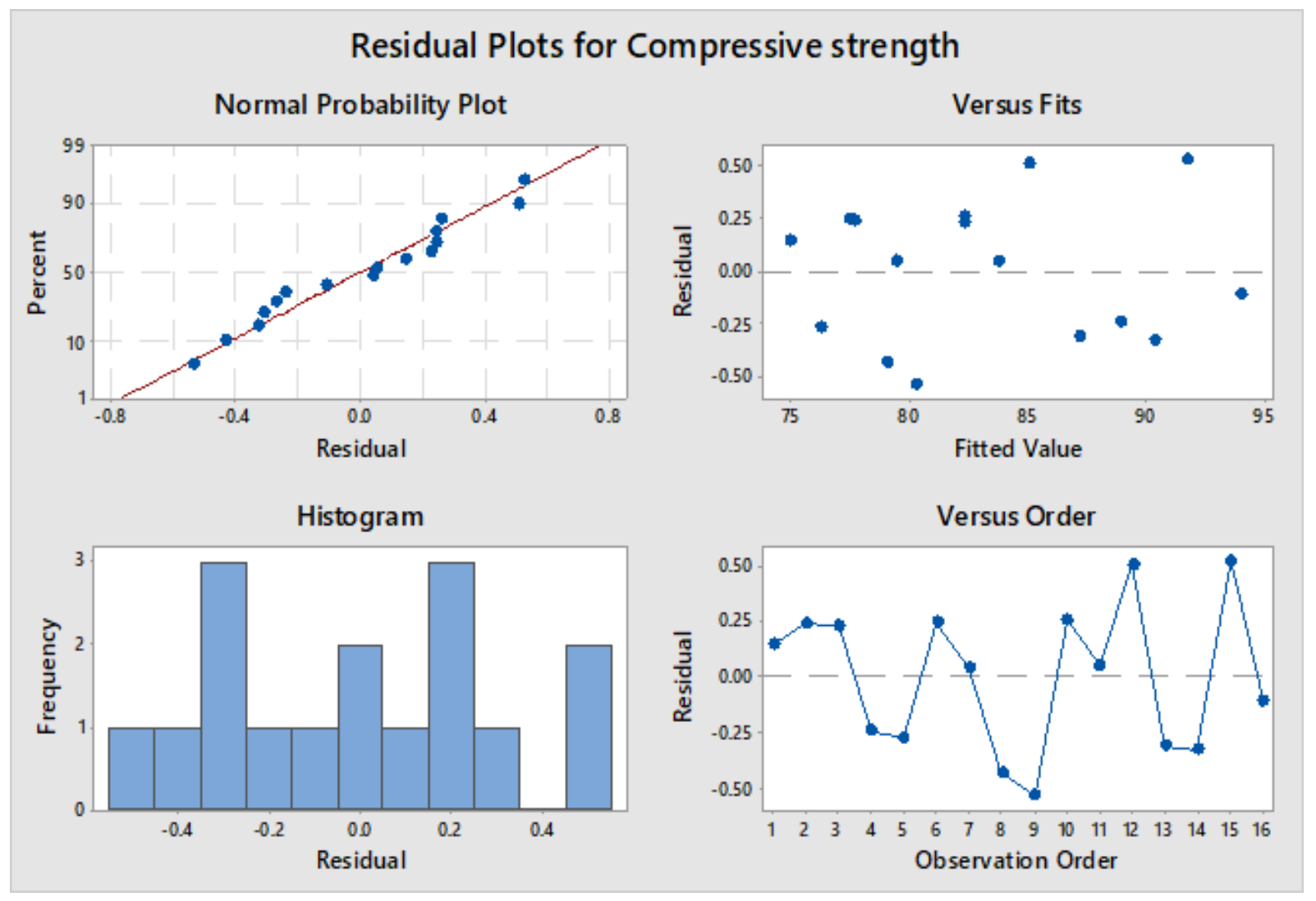

Figure 8. Residual plot for compressive strength Vs polypropylene andsteel fibers 


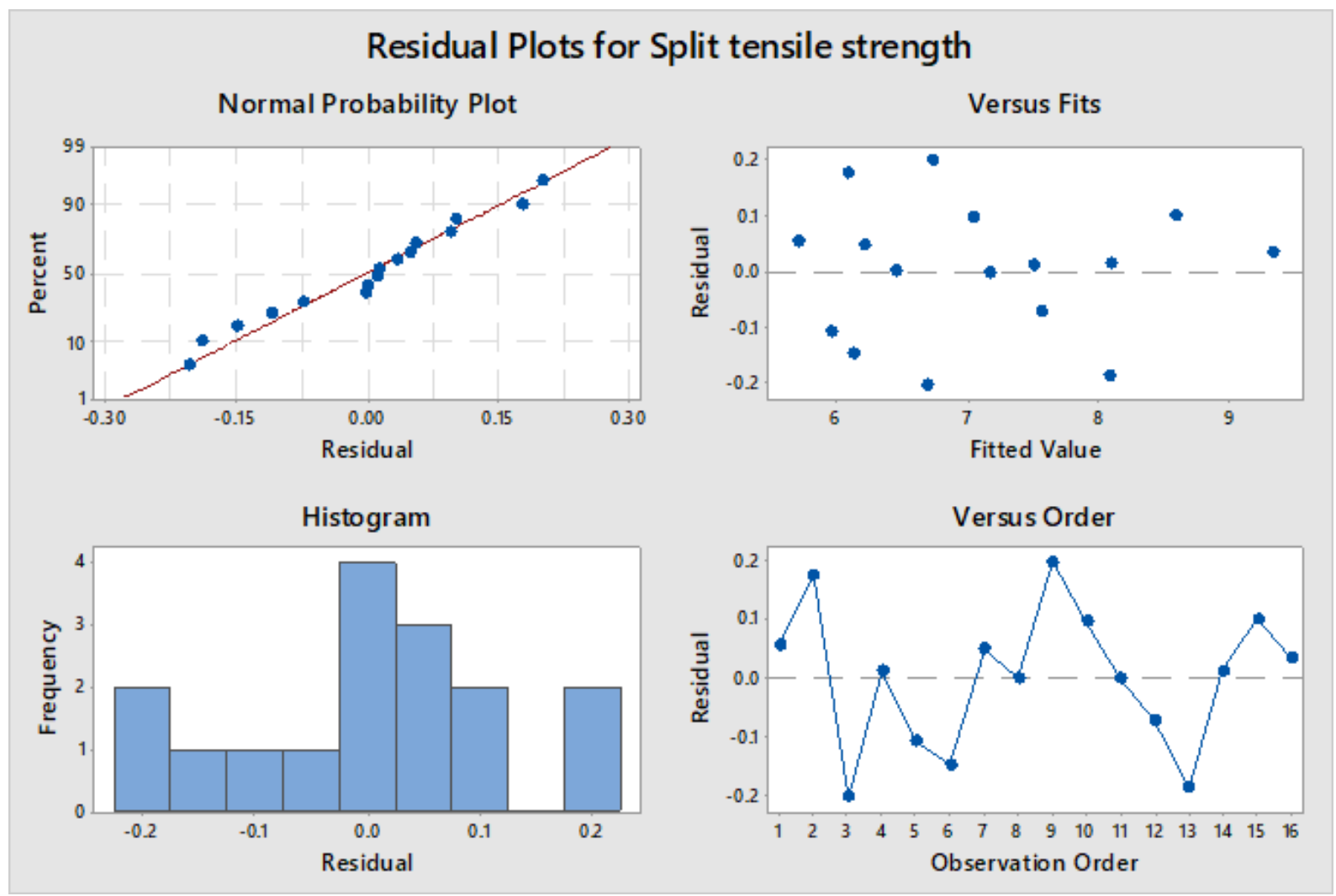

Figure 9. Residual plot for split tensile strength Vs polypropylene andsteel fibers

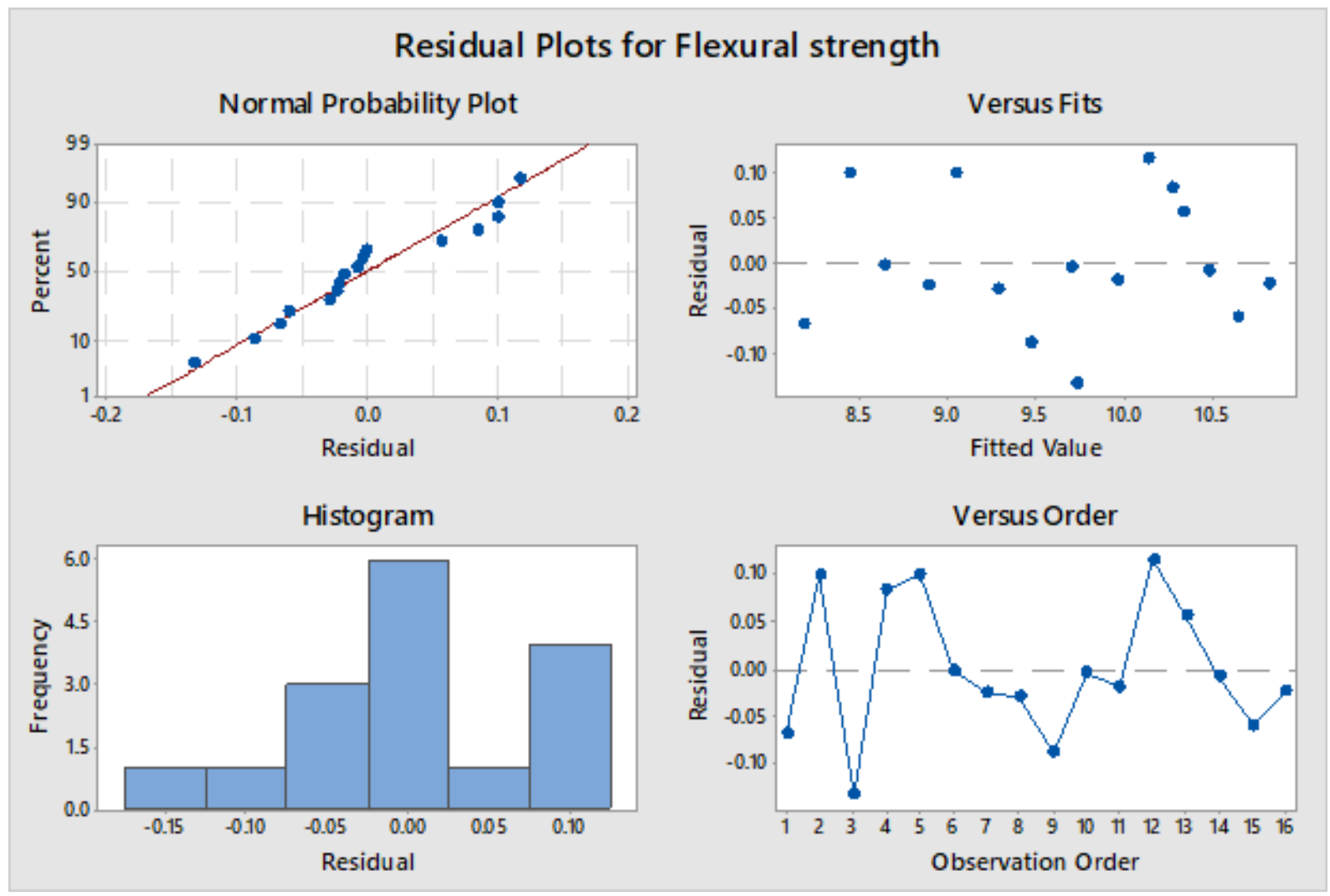

Figure 10. Residual plot for flexural strength Vs polypropylene and steelfibers 


\subsection{Optimization}

Optimization was used with the aim of finding an optimized quantity among all mixes, performed by using Minitab software. The upper limit, lower limit and goal were set to perform the optimization, displayed in Table 5. The optimized solution was found with a desirability of 0.881, Table 6 shows the optimized mixes. The optimization values of responses were 93.9 MPa, 9.33 MPa and $10.79 \mathrm{MPa}$ of compressive strength, split tensile strength and flexural strength, respectively.

Table 5. Criteria setting for optimization

\begin{tabular}{|c|c|c|c|}
\hline Variable/responses & Goal & Lowerlimit & Upperlimit \\
\hline Cement & In range & $392 \mathrm{~kg}$ & $460 \mathrm{~kg}$ \\
\hline Steel fibers & In range & 0 & 1.5 \\
\hline Polypropylene fiber & In range & 0 & 1 \\
\hline Compressive strength & Maximize & 68.85 & 94.0082 \\
\hline Split tensile strength & Maximize & 5.49 & 9.37 \\
\hline Flexural strength & Maximize & 8.12 & 10.81 \\
\hline
\end{tabular}

Table 6. Optimized mix

\begin{tabular}{|c|c|}
\hline Materials & Quantity (Kg) \\
\hline Cement & 392 \\
\hline Steel fibers & 1.5 \\
\hline Polypropylene fiber & 1 \\
\hline Compressive strength & 93.9 \\
\hline Split tensile strength & 9.33 \\
\hline Flexural strength & 10.79 \\
\hline
\end{tabular}

\section{Conclusions}

- In the proposed research focused to develop the strengthening of high-performance concrete using fibers. Two different fibers are used to strengthen the concrete; here hybrid fibers are used to enhance the structures. Three different types of specimens are investigated (cubes, cylinders, and prisms) to find out the compressive strength, split tensile strength, and flexural strength. In this experimental investigation at $\mathrm{w} / \mathrm{c}$ ratio is used such as 0.38 . Totally 34 specimens are examined with varying two fiber percentage. The results of the test are taken by curing specimens for 28 days.

- The test results showed that the use of hybrid fibers with high percentages is one of the effective and economical methods to improve structural parameters of high-performance concrete. Concrete specimens with steel and polypropylene fibers have shown moderate improvement in compressive strength and significant improvement in splitting tensile and flexural strengths for two w/c ratios. The maximum compressive strength attained in hybrid HPFRC9 are
93.9 and 102.65 Mpa, split tensile strength is 9.37, and $10.42 \mathrm{Mpa}$, and flexural strength is 10.79 and 13.82 in both type I and II (w/c ratio $=0.38$ and 0.28 ). The hybrid fibers work in perfect mix and get enhancements in mechanical performance.

- Due to the fiber bond effect in concrete matrix, mechanical properties are improved, in particular, the flexural/ splitting tensile strengths improvement are higher. In low $\mathrm{W} / \mathrm{b}$ ratio of $\mathrm{HPC}$, densification of concrete matrix is higher and hence fiber matrix bond effect is high. This is the cause for the achievement of better performance in concrete mix. In hybrid FRC, due to the synergy between fibers and concrete matrix, one fiber is the most responsible for the enhancement of strength and the other fiber is restraining, bridging and controlling the cracks. This fiber synergic effect in HyFRC highly improves the post peak response and toughness of FRC. This was reported by earlier researchers and was also found this effect while testing the HyFRC specimens in flexural.

- Response surface method (RSM) was applied on experimental data utilizing regression analysis and developed the models for the prediction of mechanical properties and the average error obtained was within the acceptable limits; optimum quantities of the materials were also obtained.

\section{Acknowledgments}

The authors acknowledge the Pondicherry Engineering College, Pondicherry, India for providing laboratory testing facilities.

\section{REFERENCES}

[1] Li, B., Chi, Y., Xu, L., Shi, Y. and Li, C., 2018. Experimental investigation on the flexural behavior of steel-polypropylene hybrid fiber reinforced concrete. Construction and Building Materials, 191, pp.80- 94.

[2] Meda, A., Rinaldi, Z., Spagnuolo, S., De Rivaz, B. and Giamundo, N., 2019. Hybrid precast tunnel segments in fiber reinforced concrete with glass fiber reinforced bars. Tunnelling and Underground Space Technology, 86, pp.100-112.

[3] Yoddumrong, P., Rodsin, K. and Katawaethwarag, S., 2018, April. Experimental study on compressive behavior of low and normal strength concrete confined by low-cost glass fiber reinforced polymers (GFRP). In 2018 Third International Conference on Engineering Science and Innovative Technology (ESIT) (pp. 1-4). IEEE.

[4] Lee, J.H., 2017. Influence of concrete strength combined with fiber content in the residual flexural strengths of fiber reinforced concrete. Composite Structures, 168, pp. 216-225. 
[5] Khan, M. and Ali, M., 2018. Effect of super plasticizer on the properties of medium strength concrete prepared with coconut fiber. Construction and Building Materials, 182, pp.703-715.

[6] Abbass, W., Khan, M.I. and Mourad, S., 2018. Evaluation of mechanical properties of steel fiber reinforced concrete with different strengths of concrete. Construction and Building Materials, 168, pp.556-569.

[7] Erdal, H.I., Karakurt, O. and Namli, E., 2013. High performance concrete compressive strength forecasting using ensemble models based on discrete wavelet transform. Engineering Applications of Artificial Intelligence, 26(4), pp.1246-1254.

[8] Mínguez, J., González, D.C. and Vicente, M.A., 2018. Fiber geometrical parameters of fiber-reinforced high strength concrete and their influence on the residual post-peak flexural tensile strength. Construction and Building Materials, 168, pp.906-922.

[9] Bi, Y.Z., Zhang, D.L. and Hu, J.H., 2012. Application of modified polypropylene (crude) fibers concrete to strengthen the support structures in deep mine roadway. Journal of Coal Science and Engineering (China), 18(4), pp.379-384.

[10] Younis, K.H., Ahmed, F.S. and Najim, K.B., 2018, September. Effect of Recycled-Steel Fibers on Compressive Strength and Shrinkage Behavior of Self-Compacting Concrete. In 2018 11th International Conference on Developments in eSystems Engineering (DeSE) (pp. 268-272). IEEE.

[11] N. Banthia et al., 2014 "Fiber synergy in Hybrid Fiber Reinforced Concrete (HyFRC) in flexure and direct shear", Cement and Concrete 48, pp.91-97.

[12] R Perumal, 2015 "Correlation of compressive strength and other engineering properties of high performance steel fiber reinforced concrete". Journal of Materials in Civil Engineering 27 (1), pp.1-17.

[13] P Ramadoss, 2014. "Combined effect of silica fume and steel fiber on the splitting tensile strength of high strength concrete, International Journal of Civil Engineering (Transaction A Civil) 12 (1), pp.96-103.

[14] P Ramadoss \& K Nagamani, 2012. Statistical methods of investigation on the compressive strength of high-performance steel fiber reinforced concrete, Computers and Concrete 9 (2), pp.53-169.

[15] Ramadoos Perumal, 2012. "Modelling for the evaluation of strength and toughness of high-performance fiber reinforced concrete, Journal of Engineering Science and Technology 7 (3), pp.280-291.

[16] Eethar Thanon Dawood \& Mahyuddin Ramli b 2012. Durability of high strength flowing concrete with hybrid fibres, Construction and Building Material 35, pp.521-530.

[17] IS 516-2004, Method of tests for strength of concrete.
[18] ASTM C696 (1990) —-Test For Splitting Tensile Strength of Cylindrical Concrete Specimens\|, American Society for Testing and Materials, Philadelphia, Pennsylvania, USA.

[19] Standard Test Method for Flexural Strength of Concrete (Using Simple Beam With Third Point Loading), ASTM C 78, 1994 Annual Book of ASTM Standards, Vol. 04.02 (American Society for Testing and Materials, Philadelphia, PA, 1994).

[20] IS 2009-10262, Guidelines for Concrete Mix Design Proportioning, Bureau of Indian Standards. 2009.

[21] Rahman, N.A., Hassan, A., Yahya, R., Lafia-Araga, R.A. and Hornsby, P.R., 2012. Polypropylene/glass fiber/nanoclay hybrid composites: morphological, thermal, dynamic mechanical and impact behaviors. Journal of Reinforced Plastics and Composites, 31(18), pp.1247-1257.

[22] Huang, L., Xu, L., Chi, Y., Deng, F. and Zhang, A., 2019. Bond strength of deformed bar embedded in steel-polypropylene hybrid fiber reinforced concrete. Construction and Building Materials, 218, pp.176-192.

[23] Zahiri, F. and Eskandari-Naddaf, H., 2009 'Optimizing the compressive strength of concrete containing micro-silica, nano-silica, and polypropylene fibers using extreme vertices mixture design". Frontiers of Structural and Civil Engineering, pp.1-10.

[24] de Souza Castoldi, R., de Souza, L.M.S. and de Andrade Silva, F., 2019. 'Comparative study on the mechanical behavior and durability of polypropylene and sisal fiber reinforced concretes". Construction and Building Materials, 211, pp.617-628.

[25] Reddy, Panga Narasimha, Bharat Bhushan Jindal, Bode Venkata Kavyateja, and A. Narender Reddy. 2020 "Strength enhancement of concrete incorporating alccofine and SNF based admixture." Advances in concrete construction 9, no. 4: 345-354.

[26] Kavyateja, Bode Venkata, J. Guru Jawahar, and C. Sashidhar. 2020 "Effect of alccofine and fly ash on analytical methods of self-compacting concrete." Innovative Infrastructure Solutions 5, no. 3: 1-11.

[27] Reddy, Panga Narasimha, and Bode Venkata Kavyateja. 2020 "Durability performance of high strength concrete incorporating supplementary cementitious materials." Materials Today: Proceedings 33: 66-72.

[28] Wasim Abbass et al. 2018 "Evaluation of Mechanical Properties of Steel Fiber Reinforced Concrete with Different Strengths of Concrete." Construction and Building Materials, 168, pp.556-569.

[29] Vaid Afroughsabet, Togay Ozbakkaloglu 2015 "Mechanical and Durability Properties of High-Strength Concrete Containing Steel and Polypropylene fibers." Construction and Building Materials, 94, pp.73-82.

[30] Vitor Moreira et. al. 2018 "On the Mechanical Behavior of Polypropylene, steel and Hybrid Fiber Reinforced Concrete" Construction and Building Materials, 188, pp.280-291. 